\title{
Ion channel disorders: still a fascinating topic-news on episodic ataxia type 1
}

\section{Michael Strupp}

Ion channel disorders are one of the most challenging areas in neurology and basic neuroscience with more than 27500 results in a PubMed search and an increasing annual publication rate. They have become of particular relevance in muscle disorders (eg, myotonias), epilepsy (eg, benign familial neonatal epilepsy), paraneoplastic syndromes (eg, antibodies against ion channels as in Isaac's syndrome) cerebellar ataxias (eg, episodic ataxias ${ }^{1}$ ) or headache (eg, familial hemiplegic migraine). Mutations can affect voltage-gated channels or ligand-gated channels as, for instance, in congenital myasthenic syndromes. Basically, mutations of ion channel genes can have three consequences: loss-of-function ('nonsense mutations') when no functional ion channel protein is expressed (due to heterozygosity there is, however, still one normal channel protein, leading to a reduced density of ion channels and ion currents); a change-of-function ('missense mutations') leading to an altered ion channel protein, which can change the activation or inactivation potentials, kinetics of opening or closing of the channel or change the ion selectivity, all of which may have a major impact on the function of the ion channel, leading either to a gain-of-function or a reduction in function; change of the trafficking of the ion channel; or incorporation into the membrane. In summary, all these mutations can increase or decrease the excitability of nerve cells, dendrites or axons.

Our knowledge in the field of ion channels has considerably increased over the last 20 years, ${ }^{2}$ in particular due to the combined use of four techniques: first, gene sequencing, allowing identification of the different mutations and thereby a precise genetic diagnosis; second, patch clamp technique, ${ }^{3}$ which can be applied as recordings of single ion channels or whole-cell recordings to characterise the physiology of ion channels, but also to evaluate the changes in functions in mutated ion channels. The application of the patch clamp technique requires functional expression of the ion channels. Third, this can be

Correspondence to Professor Michael Strupp, Department of Neurology and German Center for Vertigo and Balance Disorders, University Hospital Munich, Campus Grosshadern, Marchioninistrasse 15, 81377 Munich, Germany; michael.strupp@med.unimuenchen.de combined with immunocytochemistry to evaluate the site and density of expression in the cell membrane. ${ }^{4}$ Fourth, animal models of ion channel disorders, for example, the tottering mouse as a model for episodic ataxia type 2 (EA2); in such models, the effects of drugs can also be examined, for example, chlorozoxazone or 4-aminopyridine in the tottering, ${ }^{5}{ }^{6}$ which has been shown to be efficient as a prophylactic treatment for EA2 in humans. ${ }^{7}$

Many neurological ion channel disorders are characterised by paroxysmal attacks. A classic example is EAs with the leading symptom of recurrent episodes of ataxia. ${ }^{8}$ At least seven different types have been described. The two most important subtypes are episodic ataxia type 1 and 2 (EA1, EA2). EA2 is also characterised by recurrent attacks of ataxia and patients typically also have pronounced central oculomotor dysfunction, in particular downbeat nystagmus syndrome, in the attack-free interval. These patients respond very well to treatment with 4-aminopyridine. ${ }^{7}$ EA1 is clinically also characterised by short attacks of limb ataxia, dysarthria, nystagmus, tremor and/ or gait impairment. The attacks can be triggered by exercise, stress or alcohol. Attacks typically last only seconds to minutes. Most patients also have persistent neuromyotonia. EA1 is caused by heterozygous mutations of fast $\mathrm{K}+$ channels (the 'delayed rectifier'), which are opened by depolarisation having a hyperpolarising effect on the membrane potential after an action potential and thus limiting neuronal excitability. Mutations of the so-called $\mathrm{K}_{\mathrm{v}} 1.1$ subunits of these fast potassium channels cause an increased excitability of neurons and prolonged duration of action potentials, leading to repetitive axonal activity (causing neuromyotonia). The exact mechanisms that lead to attacks of cerebellar ataxia are not known so far.

In the current paper by Susan Tomlinson, Michael Hanna, Dimitri Kullmann and others-a real English-Australian cooperation-15 patients from four families in three countries were studied. ${ }^{9}$ All had a history of short episodes of cerebellar dysfunction; in one family, the documentation of typical EA1 symptoms dated back to 1928. Attacks were typically induced by exercise, meaning that none of the subjects were able to participate in sports or to run at all. In 4 of the 15 subjects, vocation was also affected. As a new observation, four subjects had a hearing impairment, which was identified as a new finding in EA1. In three of the four families, three new mutations were found. All three new mutations caused a loss of $\mathrm{K}_{\mathrm{v}} 1.1$ channel function ('nonsense mutations'). Expression of the ion channels in combination with immunocytochemistry showed that the trafficking of the ion channels was not impaired. Coexpression of the mutated with the wild type produces a smaller peak current density compared with the wild type alone as well as a significant positive shift of channel activation.

In this study, four unreported families with the phenotype of EA1 were described and very carefully analysed using state-of-the-art patch clamp and molecular biology techniques. The major new findings were: (1) the presence of deafness in four patients, which is of particular interest as $\mathrm{K}_{\mathrm{v}} 1.1$ is expressed in the auditory brainstem. (2) Exercise-induced and stress-induced impairment of vocational duties, which can also have a major impact on professional and daily living activities. (3) The very first well documented case of EA1 is presented, dated back to 1928 .

At the end of their paper, the authors also carefully discuss the pathophysiology and genetics of EA1. They point out that the variability in phenotype is evidently the result of non-genetic factors. They point out that the reason for the intermittent manifestation is so far not known. New perspectives for the treatment of EA1 are also given: agents that enhance the current (currently there is potassium channel opener ritigabine available which, however, acts on slow voltage-gated Kv7 potassium channel only and is a new treatment option for epileptic seizures; ${ }^{10}$ overexpression of $\mathrm{K}_{\mathrm{v}} 1.1$, which has been successfully used in a rodent model of neocortical epilepsy with a lentiviral vector; and the use of acetazolamide, which may diminish the frequency and severity of the episodes as well as carbamazepine or phenytoin which have an effect on neuromyotonia (for Ref. see ref. 9). All in all, this paper broadens our knowledge of the clinical spectrum of EA1, in particular in terms of impaired hearing and impairment of vocalisation. The new mutations cause similar deficits to previously described $\mathrm{K}_{\mathrm{v}} 1.1$ mutations. Finally, the current deficit in symptomatic and causative treatment of EA1 was pointed out.

Contributors The work was done by MS.

Competing interests None.

Provenance and peer review Commissioned; internally peer reviewed.

To cite Strupp M. J Neurol Neurosurg Psychiatry 2013;84:1063-1064. 


\section{Editorial commentary}

Received 22 January 2013

Accepted 29 January 2013

Published Online First 1 March 2013

\section{SLinked}

- http://dx.doi.org/10.1136/jnnp-2012-304131

J Neurol Neurosurg Psychiatry 2013;84:1063-1064. doi:10.1136/jnnp-2012-304857

\section{REFERENCES}

1 Rajakulendran S, Kaski D, Hanna MG. Neuronal $\mathrm{P} / \mathrm{Q}$-type calcium channel dysfunction in inherited disorders of the CNS. Nat Rev Neurol 2012;8:86-96.

2 Kullmann DM. Neurological channelopathies. Annu Rev Neurosci 2010;33:151-72.

3 Hille B. Ionic channels of excitable membranes. New York City, New York, USA: Palgrave Macmillan, 2001.

4 Kullmann DM, Waxman SG. Neurological channelopathies: new insights into disease mechanisms and ion channel function. J Physiol 2010;588:1823-7.

5 Alvina K, Khodakhah K. KCa channels as therapeutic targets in episodic ataxia type-2. J Neurosci 2010;30:7249-57.

6 Alvina K, Khodakhah K. The therapeutic mode of action of 4-aminopyridine in cerebellar ataxia. J Neurosci 2010;30:7258-68.
7 Strupp M, Kalla R, Claassen J, et al. A randomized trial of 4-aminopyridine in EA2 and related familial episodic ataxias. Neurology 2011;77:269-75.

8 Baloh RW. Episodic ataxias 1 and 2. Handb Clin Neurol 2012;103:595-602.

9 Tomlinson SE, Rajakulendran S, Tan SV, et al. Clinical, genetic, neurophysiological and functional study of new mutations in episodic ataxia type 1. J Neurol Neurosurg Psychiatry 2013;84: 1107-12.

10 Orhan G, Wuttke TV, Nies AT, et al. Retigabine/Ezogabine, a KCNQ/K(V)7 channel opener: pharmacological and clinical data. Expert Opin Pharmacother 2012;13:1807-16. 


\section{Ion channel disorders: still a fascinating topic --news on episodic ataxia type 1}

Michael Strupp

J Neurol Neurosurg Psychiatry 2013 84: 1063-1064 originally published online March 1, 2013

doi: 10.1136/jnnp-2012-304857

Updated information and services can be found at:

http://jnnp.bmj.com/content/84/10/1063

\section{These include:}

References This article cites 9 articles, 4 of which you can access for free at: http://jnnp.bmj.com/content/84/10/1063\#BIBL

Email alerting Receive free email alerts when new articles cite this article. Sign up in the service box at the top right corner of the online article.

Topic Articles on similar topics can be found in the following collections Collections

Epilepsy and seizures (739)

Brain stem / cerebellum (629)

Drugs: CNS (not psychiatric) (1747)

Ear, nose and throat/otolaryngology (188)

Headache (including migraine) (389)

Musculoskeletal syndromes (490)

Neuromuscular disease (1194)

Pain (neurology) (657)

Peripheral nerve disease (595)

Muscle disease (233)

\section{Notes}

To request permissions go to:

http://group.bmj.com/group/rights-licensing/permissions

To order reprints go to:

http://journals.bmj.com/cgi/reprintform

To subscribe to BMJ go to:

http://group.bmj.com/subscribe/ 